Published in final edited form as:

ACS Nano. 2016 March 22; 10(3): 3214-3221. doi:10.1021/acsnano.5b05211.

\title{
Spearhead Nanometric Field-Effect Transistor Sensors for Single-Cell Analysis
}

\author{
Yanjun Zhang ${ }^{\# \dagger}$, Jan Clausmeyer ${ }^{\# \ddagger}$, Babak Babakinejad ${ }^{\# \dagger}$, Ainara López Córdoba ${ }^{\dagger}$, \\ Tayyibah Ali ${ }^{\dagger}$, Andrew Shevchuk ${ }^{\dagger}$, Yasufumi Takahashi ${ }^{\S}$, Pavel Novak", Christopher \\ Edwards $^{\dagger}$, Max Lab ${ }^{\perp}$, Sahana Gopal ${ }^{\dagger}$, Ciro Chiappini ${ }^{\#}$, Uma Anand ${ }^{\dagger}$, Luca Magnani ${ }^{\nabla}$, R. \\ Charles Coombes $^{\nabla}$, Julia Gorelik ${ }^{\perp}$, Tomokazu Matsue ${ }^{\S}$, Wolfgang Schuhmann ${ }^{\star}, \ddagger$, David \\ Klenerman $^{*}$, , Elena V. Sviderskaya ${ }^{*}, \mathrm{O}$, and Yuri Korchev ${ }^{*}, \dagger$ \\ tDepartment of Medicine, London W12 0NN, United Kingdom \\ ${ }^{\perp}$ Department of Cardiac Medicine, National Heart and Lung Institute, London W12 0NN, United \\ Kingdom \\ ${ }^{\nabla}$ Department of Surgery and Cancer, Imperial College London, London W12 0NN, United \\ Kingdom \\ ¥Analytical Chemistry-Center for Electrochemical Sciences (CES), Ruhr-Universität Bochum, \\ Universitätsstraße 150, 44780 Bochum, Germany \\ §Advanced Institute for Materials Research, Tohoku University, Sendai 980-8577, Japan \\ "School of Engineering and Materials Science, Queen Mary, University of London, London E1 \\ 4NS, United Kingdom \\ \#Department of Materials, Imperial College London, London SW7 2AZ, United Kingdom \\ -Department of Chemistry, University of Cambridge, Cambridge CB2 1EW, United Kingdom \\ ${ }^{\circ}$ Cell Biology and Genetics Research Centre, St. George's University of London, London SW17 \\ ORE, United Kingdom \\ \# These authors contributed equally to this work.
}

\section{Abstract}

\begin{abstract}
Nanometric field-effect-transistor (FET) sensors are made on the tip of spear-shaped dual carbon nanoelectrodes derived from carbon deposition inside double-barrel nanopipettes. The easy fabrication route allows deposition of semiconductors or conducting polymers to comprise the transistor channel. A channel from electrodeposited poly pyrrole (PPy) exhibits high sensitivity toward $\mathrm{pH}$ changes. This property is exploited by immobilizing hexokinase on PPy nano-FETs to give rise to a selective ATP biosensor. Extracellular pH and ATP gradients are key biochemical constituents in the microenvironment of living cells; we monitor their real-time changes in relation
\end{abstract}

\footnotetext{
"Corresponding Authors (Wolfgang Schuhmann) wolfgang.schuhmann@ rub.de. "(David Klenerman) dk10012@cam.ac.uk. "(Elena V. Sviderskaya) esviders@sgul.ac.uk. (Yuri Korchev) y.korchev@imperial.ac.uk.

Supporting Information

Notes

The authors declare no competing financial interest.
} 
to cancer cells and cardiomyocytes. The highly localized detection is possible because of the high aspect ratio and the spear-like design of the nano-FET probes. The accurately positioned nanoFET sensors can detect concentration gradients in three-dimensional space, identify biochemical properties of a single living cell, and after cell membrane penetration perform intracellular measurements.

\section{Keywords}

scanning probe microscopy; FET; biosensor; ATP; nanosensor; nanopipette; nanoelectrode

As nanotechnology advances, nanomaterial-based field-effect transistor (FET) sensors ensure current amplification while maintaining a high signal-to-noise ratio.1-3 Assembly and interfacing of the sensing nanomaterials rely on elaborate nanofabrication protocols. 4 FET biosensors based on conducting polymers, especially poly pyrrole (PPy) sensors are advantageous because of the ease of electropolymerization and functionalization,5,6 good biocompatibility, and chemical stability.7,8 However, these sensors are restricted by their chip-like design exhibiting relatively large (several micrometer) electrode dimensions. These have limited their ability to perform highly localized measurements in small volumes, especially in biological samples such as individual cells.1,9-11

Carbon-based electrodes showed excellent properties in detecting the characteristics of single cells, 12 in detection of single nucleotide polymorphisms of DNA, and early diagnosis of cancers. 13 To reduce the sensor size, our group has recently developed a method to rapidly and reliably fabricate nanometer-size dual carbon electrodes (DCEs) by depositing pyrolytic carbon into a quartz $\Theta$-nanopipette.14,15 These DCEs can be functionalized and combined with SICM control for high resolution chemical sensing and topographical imaging of living cells.16-19 However, the weak amperometric signal generated by the small analyte volume of these nanometric DCEs is limited by the electronic capabilities of commercial current amplifiers. To overcome this weakness, we present a highly sensitive PPy FET on the nanometer-scaled tip of the spear-shape DCEs.

Normal cell survival requires the maintenance of a relatively constant extracellular microenvironment with a $\mathrm{pH}$ value of around 7.4. In contrast, cancer cells function at a lower $\mathrm{pH}$ level consequent on their intensive respiratory $\mathrm{CO}_{2}$ and lactic acid production.20 Such extracellular acidity has emerged as a hallmark of cancer cells, which can dramatically influence cell proliferation, growth, and apoptosis.21,22 Our newly developed nanobiosensors exhibit high sensitivity toward local variations in the $\mathrm{pH}$ value and can be used to detect the extracellular acidosis of cancer cells.

In response to physiological stimuli cells can release adenosine triphosphate (ATP) in an autocrine/paracrine manner. This can interact with a variety of membrane ionotropic P2X or G-protein-coupled metabotropic P2Y receptors to affect downstream signaling cascades.2325 Given the importance of different P2 receptors sensing changes in local concentrations of ATP, detecting ATP gradients in close proximity to the cell surface might enable the discovery of previously unrecognized purinergic signaling mechanisms.26 Previous sensing approaches relying on liquid chromatography, luciferase assays,25,27-29 amperometry, 
30,31 FET devices32 or the response of cells to ATP itself33 have revealed that cells secrete up to micromolar concentrations of ATP. However, neither sensitivity nor spatial resolution allows these available sensors either to be accurately positioned or to measure nanomolar range changes in the gradient of extracellular ATP locally.

It is well-known that hexokinase catalyzes the addition of phosphate from ATP to glucose, which releases one proton per molecule ATP in the glycolysis reaction and can be detected by biosensors.34 On the basis of our pH-sensitive PPy-FET, and by modification of the PPy channel with hexokinase we present a sensitive ATP nanosensor which due to its spear-shape enables the measurement of the extracellular ATP gradient in three dimensions around single living cells.

\section{Results}

A laser-pulled quartz $\Theta$-capillary simply fabricates a doublebarrel nanopipette. Then, pyrolytic decomposition of butane deposits conductive carbon, and produces two individually addressable carbon nanoelectrodes, separated by a few nanometer thin glass wall14 (Figure 1, Figure 2). Raman spectroscopy is particularly well suited for the characterization of carbon materials. The Raman spectrum of our carbon electrodes shows the $\mathrm{D}$ and $\mathrm{G}$ band at 1367 and $1576 \mathrm{~cm}^{-1}$, respectively. This, together with the absence of the $G^{\prime}$ band indicates that the carbon material is largely graphitic but shows some defects. 16 Our previous study has demonstrated that the geometry of nanoscale dual carbon electrodes can be determined precisely by SEM, and their size and working surface can also be characterized based on the steady-state limiting current in electrochemical measurements. 15 To generate a field-effect transistor (FET), a semiconducting material is deposited on the dual carbon electrode to comprise the channel of the transistor. Then, to create a specific FET sensor, biological receptor molecules that recognize or catalytically convert a target analyte with high selectivity are immobilized to the sensing transistor channel. We show the deposition of PPy, which is anodically electropolymerized by applying a potential sweep up to $+0.6 \mathrm{~V}$ vs $\mathrm{Ag} / \mathrm{AgCl}$ to both electrodes simultaneously. PPy is deposited as a thin film exclusively on the apex of the dual carbon nanoelectrode, as shown by electron microscopy (Figure 2). The formed PPy transistor channel has a diameter of about $200 \mathrm{~nm}$.

After electrodeposition of PPy the nanoelectrode tip comprises a fully functional FET with the two carbon nanoelectrodes acting as drain and source and the PPy nanojunction as the channel (Figure 3). The drain-source current is linearly dependent on the applied drainsource voltage (typically held at $5 \mathrm{mV}$ ) (Supplementary Figure 2a) and can be reversibly switched by applying different gate voltages with respect to an external $\mathrm{Ag} / \mathrm{AgCl}$ electrode (Figure 3b).

When the potential is below $-0.2 \mathrm{~V}$, the PPy is reduced, and hence the junction becomes insulating and the source-drain current vanishes. Upon applying more anodic potential the PPy channel is oxidized and becomes conductive due to the insertion of positive charge carriers into the polymer backbone. The small faradaic "leakage" current passed into the transistor gate to oxidize/reduce the PPy is negligibly small compared to the drain-source current passing through the PPy channel (Supplementary Figure 2b,c). The large and robust 
drain-source current signal ensures a high signal-to-noise ratio. Moreover, the drain-source current is strongly dependent on the $\mathrm{pH}$ value, turning the PPy nano-FET into a sensitive $\mathrm{pH}$ sensor.

As described earlier,35 the protonation of pyrrolic nitrogen in the PPy nanojunction has two effects: First, a general increase of conductance is observed which leads to higher drainsource currents. Second, a shift in the $I-V_{\mathrm{G}}$ curve is observed due to the electrical potential change induced by proton accumulation/depletion at different $\mathrm{pH}$ values that adds to the externally applied gate voltage (Figure $3 \mathrm{~b}-\mathrm{d}$ ). Current-voltage curves normalized by the peak current show a voltage shift of $51 \mathrm{mV}$ per $\mathrm{pH}$ unit, close to the value of $59 \mathrm{mV}$ predicted for Nernstian behavior (Figure 3d). Alternatively, $\mathrm{pH}$ measurements can be performed reliably by extracting either $I_{\mathrm{DS}}$ at the current peak or $I_{\mathrm{DS}}$ averaged over the full $I-V_{\mathrm{G}}$ curve. The calibration curves of either the average or the peak value of drain-source currents exhibit linear sensitivity toward the proton concentration (Figure 3c). Instead of continuously sweeping the gate voltage, the PPy nano-FET can also be employed at a constant gate voltage; however, with slightly nonlinear distortions of the calibration curve (Supplementary Figure 3).

$\mathrm{pH}$-sensitive probes are fabricated with a high success rate of about $90 \%$ including the initial pulling step. Because of the probes' high sensitivity and small tip dimensions it becomes possible to follow small $\mathrm{pH}$ changes $(\approx 0.1 \mathrm{pH}$ units) when investigating the local $\mathrm{pH}$ around cancer cells and in tumor tissue. The corresponding $\mathrm{pH}$ calibration shows a linear dependence of the drain-source current on the $\mathrm{pH}$ value in the physiologically relevant range from $\mathrm{pH} 5$ to $\mathrm{pH} 7.5$ (Figure 3f). The sensitivity toward protons, expressed as $1 / \mathrm{G}_{0} \cdot \Delta G / \Delta \mathrm{pH}$, with the conductance $G=I_{\mathrm{DS}} / V_{\mathrm{DS}}$ and $G_{0}$ the conductance at $\mathrm{pH} 7$ amounts to $-0.5 \pm 0.1$ $\mathrm{pH}^{-1}$ in the linear range. The sensor has a response time of a few seconds which is sufficiently fast to track $\mathrm{pH}$ changes when moved in the vicinity of cells. When the FET probe approaches a sample of breast tumor tissue, it monitors $\mathrm{pH}$ changes in real-time (Figure 3g). The measured value of $\mathrm{pH}$ is 6.2 when the sensor is inserted into the tissue, compared to $\mathrm{pH} 6.7$ measured outside of the tissue. This difference reflects the acidification characteristic of tumors. 20

Melanocytes are pigment-producing cells in human skin and also the cells that become cancerous in malignant melanoma. Early detection of melanoma is critical to avoid disfiguring, function impairing, or life threatening consequences. Compared to normal melanocytes, melanoma cells can acidify their extracellular environment because of high glucose uptake rates, increased glycolysis, and the accumulation of lactic acid.36,37 As expected, a pH decrease in the microenvironment of cells was only detected in a cluster of cultured melanoma cells (Figure 3h) but not in normal melanocytes (Supplementary Figure 4a). In the confined space of the melanoma cluster a $\mathrm{pH}$ change from 7.0 to 6.3 is detected. In these experiments, prior to insertion of the sensor into the cluster, the cluster was formed by moving and gathering cells using the FET probe as a manipulation tool. In contrast, there is no noticeable sensor response when the probe approaches a single isolated melanoma cell (Figure 3i). Presumably, significant amounts of extracellular protons are only accumulated if cells are located in a confined space obstructing the rapid diffusion of protons away from their source. 38 
The $\mathrm{pH}$-sensitivity of the PPy-gated FET can be exploited for numerous detection schemes to detect analytes other than protons if a chemical conversion of the analyte is translated into a $\mathrm{pH}$ change. As an example, the assembly of a glucose nanobiosensor exploiting the $\mathrm{pH}$ change via biocatalytically generated gluconic acid from glucose oxidase 8 is provided in Supplementary Figure 7.

To demonstrate the possibility of making a sensor for ATP, hexokinase is added to the solution and the $\mathrm{pH}$-sensitive PPy nano-FET responds to changes in the concentration of ATP (Supplementary Figure 5). Hexokinase cleaves ATP by transferring a phosphate group to its substrate glucose and releases stoichiometric amounts of protons (Figure 4a). When the nano-FET is placed in a Petri dish containing melanoma cells and hexokinase is added, ATP released from the cells is detected exploiting the $\mathrm{pH}$ change caused by hexokinase activity (Supplementary Figure 5b,c). The ATP concentration found in the cell dish amounts to approximately $10 \mu \mathrm{M}$. To avoid global $\mathrm{pH}$ changes generated by ATP cleavage in the bulk solution that might affect cell viability, the enzyme is locally attached to the tip of the nanoFET sensor (Figure 4a). After treating the PPy-modified probe with glutaraldehyde to facilitate protein immobilization, the pipet is immersed into a solution of hexokinase. The success rate for immobilization of hexokinase is about $80 \%$, rendering an overall efficiency of about $70 \%$ to yield highly ATP-sensitive FETs from the initial nanopipettes. The hexokinase-modified nano-FET shows high sensitivity toward the presence of ATP (Figure 4 b). As expected, the drain-source current increases with increasing ATP concentration due to the local production of protons by hexokinase. The probe is capable of detecting ATP concentrations down to a limit of detection (LOD) of $10 \mathrm{nM}$ (i.e., the signal at $10 \mathrm{nM}$ is larger than the blank signal +3 standard deviations). The drain-source current linearly changes with the logarithm of ATP concentration with a sensitivity $1 / G_{0} \cdot \Delta G / \Delta \log c_{\mathrm{ATP}}$, of $0.3 \pm 0.2$ per decade of ATP concentration, with $G_{0}$ being the conductance in the absence of ATP. For concentrations higher than $10 \mu \mathrm{M}$, the calibration deviates from the linear trend (Figure 4b, bottom panel). The hexokinase-modified nano-FET sensor is a powerful tool to both measure the released ATP gradients from cells and also follow their temporal changes. When the sensor is immersed into a dish containing melanoma cells, the drain-source current rapidly rises due to the release of ATP from the cells into the solution (Figure 4c). A bare PPy nano-FET probe not modified with hexokinase on the other hand does not record any changes in drain-source current and thus indicates that the $\mathrm{pH}$ value in the solution is constant. The ATP sensor is then placed intermittently over a group of melanoma cells and over a spot which is not populated by cells and the probe is quickly moved laterally back and forth between the two positions. The corresponding trace of drain-source current shows two distinct slopes of the increase of ATP concentration. Closer to the source of ATP, that is, over the group of cells the rise rate of the ATP concentration is approximately six times faster than over the empty spot, illustrating that the nano-FET permits the identification of sources of local ATP release.

Moreover, a nano-FET probe vertically approached to a single melanoma cell is capable of detecting ATP concentration gradients in space (Figure 4d). It is important to note that the bare PPy probe without hexokinase detected no $\mathrm{pH}$ change while approaching the cell (Figure 4c and Supplementary Figure 4). Also, no interference by any other constituent of the complex biological matrix surrounding the cells is observed. The drain-source current 
signal attributed to the ATP concentration on the other hand precisely mirrors the movements of the probe toward the melanoma cell and its retraction (Supplementary Figure 6). Elevated ATP concentrations are found in close proximity of the melanoma cell while in the bulk solution less ATP is present. In addition to the spatial variations, the sensor records a gradual increase of ATP concentration in time on account of the continuous release of ATP from the melanoma cells in the dish. Even though the sensor was approached to an isolated single melanoma cell, the elevated ATP level remote from the cell is assumed to be partially caused as well by neighboring cells whose diffusion layers overlap after extended periods of time. Finally, the ATP concentration reaches more than $10 \mu \mathrm{M}$ over a large distance and several tens of $\mu \mathrm{M}$ in proximity to the melanoma cell (Figure 4d).

In a similar fashion the spearhead nano-FET is used to determine the ATP gradient originating from a single cardiomyocyte (Figure 4e). Here, submicromolar levels are found in the distance, and several $\mu \mathrm{M}$ are recorded close to the cardiomyocyte. Again, it is important to note that no $\mathrm{pH}$ change or other interference was detected with the nano-FET probe not modified with hexokinase (Supplementary Figure 4). Additionally, the probe proves to be a valuable tool to monitor ATP release as a response to cell stress caused by mechanical stimulation or hypo-osmolarity in the surrounding medium (Figure 4f). Upon touching the cell with the probe and decreasing the osmolarity by $20 \%$ distinct elevated levels of locally released ATP are detected instantaneously. Owing to its small dimensions, the FET probe may finally be used for intracellular measurements (Figure $4 \mathrm{~g}$ ). Inserting the sensor into a cardiomyocyte results in a jump of drain-source current by virtue of the sudden shift in potential applied to the PPy channel when the probe faces the additional negative contribution of the membrane potential. Shortly after, an increase in drain-source current is recorded, presumably as a result of the high intracellular ATP level.

\section{Discussion}

Compared to amperometric nanoelectrodes, FET nanodevices allow real-time monitoring of physiological information with higher sensitivity due to their intrinsic amplification capabilities and high signal-to-noise ratio. However, their fabrication requires complex protocols to place the sensing nanomaterial between the source and drain contacts. To reduce electro-chemical noise, these contacts then have to be well isolated. Moreover, the large electrode size makes their local access to biological samples such as a single cell a continuing challenge.11,38,42 Table 1 summarizes current strategies employing FET-based devices to obtain physiological information from single cells. Nanometric DCEs with two individually addressable electrodes have been readily manufactured by our group at low cost.18 These provide an effective platform with which to create novel FET nanobiosensors by generating a semiconductor link between two adjacent electrodes exposed at the tip of the spear-shaped nanopipette.

To demonstrate these capabilities we have used PPy, a conducting polymer that exhibits outstanding performance as a nanomaterial in a wide variety of sensing applications.5,6,35 Functional and sensitive PPy-FETs are obtained with a high success rate. The sensors have a sensitivity of $51 \mathrm{mV} / \mathrm{pH}$, a linear working range from $\mathrm{pH} 2.4$ to $\mathrm{pH} 7.5$ and an average response time of a few seconds, which are typical values for polymer-based $\mathrm{pH}$ sensors. 43 
The high aspect ratio of these sensors allows accurate positioning in pericellular microenvironments and performing local measurements with minimal disruption to the biological milieu. $1,9,10$

An inverted $\mathrm{pH}$ gradient across the cell membrane is a typical feature of cancer cells which are characterized by extracellular acidosis that favors tumor progression and metastasis. 21,22 For example, early detection of melanoma is critical to avoid disfiguring, function impairing, or life threatening consequences. Compared with normal melanocytes, melanoma cells adapted to grow under hypoxic conditions and shared a common phenotype by acidification of their extracellular milieu,36,37 which can be distinguished by our nanobiosensor. Moreover, tumors are heterogeneous and monitoring $\mathrm{pH}$ within a tumor is likely to be of value in the early diagnosis and identification of appropriate treatments. 44 Our nanobiosensor is proved as an accurate $\mathrm{pH}$ sensor and allows real-time monitoring of extracellular acidity in the microenvironment of cancer cells and tissues, which can be applied in early detection and treatment of cancers.

The extracellular ATP concentration is a key biochemical constituent of the microenvironment of both tumors and cardiac cells. It is well-known that hypoxia causes ATP release acting via purinoceptors.23,45 Cardiac myocytes, melanoma and many other cells have also been reported to release ATP in response to mechanical disturbance and osmotic stress.23,26,33 Our PPy-FET probes can be easily functionalized to make an ATP nanobiosensor through binding hexokinase to the PPy channel. The resulting nano-FET probe is capable of detecting ATP concentrations down to $10 \mathrm{nM}$. The sensitivity may be even further increased by optimizing the binding efficiency and activity of the ATP-detecting enzyme.46 Because of its small dimensions and its spear-like design the nanobiosensor can identify micrometric hotspots of ATP secretion and even measure the release of ATP from a single cardiomyocyte in response to mechanical and osmotic stress. The measurement is not affected by any interferents in the complex biological environment. Moreover, the nanobiosensor is capable of measuring the ATP concentration gradient of different pericellular spaces where ATP levels easily reach tens of micromolars. Similar extracellular ATP concentrations have been observed previously from neonatal cardiac myocytes. 33 Even higher levels, in the hundred micromolar range, have been found in the human melanoma microenvironment. 27

In localized measurements, the distance of the detecting device to the probed cells is closely related to the measured analyte concentration. To achieve absolute measurements, precise distance control is necessary. We envisage the use of multiple-barrel nanopipettes 47 to approach the nanobiosensor to about $100 \mathrm{~nm}$ from the cell surface under the feedback control of SICM. ATP release can be measured in close proximity to the cell without disturbance and with subcellular resolution enabling high resolution chemical imaging. However, yet the response time of a few seconds precludes the use of the sensors in fast scanning probe protocols and thus needs further optimization. Such real-time local detection of ATP release and its gradient at the single-cell level could be beneficial in the understanding of cancer cell metabolism in heterogeneous tumor populations. Efforts to employ others of the myriad of nanomaterials exhibiting semiconducting properties that give rise to viable FET sensors3-5 are currently ongoing in our laboratories. Additionally, we 
show the possibility to insert the nanometric FET device into a cell for performing intracellular measurements. In the future, after carefully assessing possible interferences in the complex cytosolic matrix, applications may be expanded to the detection of substances whose presence is restricted to the intracellular space. Overall, we expect that the small dimensions of the probe combined with high sensitivity and selectivity will allow spearhead FETs to become powerful tools for the analysis of the pericellular and intracellular environment of living cells.

\section{Methods}

\section{Chemical Reagents}

All chemicals used were of analytical grade.

\section{Fabrication of Nanopipettes}

Nanopipettes were fabricated as previously published by our laboratory.16,19 Briefly, double barrel quartz theta (o.d., $1.2 \mathrm{~mm}$, i.d., $0.9 \mathrm{~mm}$, Intracell) capillaries were pulled with a P-2000 laser puller (Sutter Instrument) using the following parameters for approximately $30 \mathrm{~nm}$ apparent radius nanoelectrodes: heat 790 , filament 3 , velocity 45 , delay 130 , and pull 90. As described previously,14,15,18 the nanopipettes were filled with propane/butane and heated under inert atmosphere in a butane flame to decompose the carbon gas and yield pyrolytic carbon inside the nanopipettes. The entire fabrication process takes about $1 \mathrm{~min}$ per electrode. The size and quality of nanoelectrodes was assessed from the steady-state current during a CV in $1 \mathrm{mM}$ ferrocenemethanol (Sigma-Aldrich) and $0.1 \mathrm{M} \mathrm{KCl}$ (Supplementary Figure 1). Only electrodes exhibiting a steady-state current smaller than 30 pA were used.

\section{Electrical/Electrochemical Measurements}

Two wires were inserted into each barrel to make a connection with the carbon and thus connect the drain and source electrode. $\mathrm{A} \mathrm{Ag} / \mathrm{AgCl}$ electrode was placed in solution acting as a pseudoreference electrode. All electrochemical potentials and gate voltages are quoted against this electrode in the corresponding solution. Both electrodes were connected to an Axopatch 700B amplifier with the DigiData 1322A digitizer (Molecular Devices), and a PC equipped with pClamp10 software (Molecular Devices). For measurements on the FET, voltages of a few millivolts, typically $5 \mathrm{mV}$, were applied between drain and source. For all measurements on cells and the associated calibrations the gate voltage was swept between -0.3 and $0.3 \mathrm{~V}$ and drain-source current was continuously measured. To extract single drain-source current values those $i-V$ curves were averaged and each value represents one cycle. $\mathrm{pH}$ calibrations were made by adding small amounts from a $0.1 \mathrm{M} \mathrm{HCl}$ stock to a solution of $120 \mathrm{mM} \mathrm{NaCl}, 5 \mathrm{mM} \mathrm{KCl}, 5 \mathrm{mM} \mathrm{MgCl}_{2}$, and $12 \mathrm{mM}$ phosphate buffer $\mathrm{pH}$ 7.4. The maximal concentration of added $\mathrm{Cl}^{-}$did not exceed $20 \mathrm{mM}$, which has only a negligible effect on the behavior of the nano-PPy-FET (Supplementary Figure 2d). When moving from $135 \mathrm{mM}$ to $155 \mathrm{~m} \mathrm{M} \mathrm{Cl}^{-}$, the shift of the electrode potential of the $\mathrm{Ag} / \mathrm{AgCl}$ pseudoreference according to the Nernst equation is less than $4 \mathrm{mV}$ and thus has no significant effect on the gate voltage. 


\section{Fabrication of Nanopipette FETs}

Pyrrole was used as received and stored under argon atmosphere. Polypyrrole was deposited by sweeping the potential of both carbon electrodes between -0.3 and $0.6 \mathrm{~V} v \mathrm{vg} / \mathrm{AgCl}$ in a deaerated solution of $0.5 \mathrm{M}$ pyrrole (Sigma-Aldrich), $0.2 \mathrm{M}$ lithium perchlorate (SigmaAldrich), and 0.1 M perchloric acid (Sigma-Aldrich) in water. Electrochemical current was continuously measured during the electrodeposition in order to monitor the growth of PPy on each electrode. To detect the formation of a bridge between the two carbon electrodes a small drain-source voltage was already applied and as soon as a significant drain-source current occurred the deposition was stopped. Before usage all FET sensors were cycled between -0.3 and $0.3 \mathrm{~V}$ in $0.1 \mathrm{M} \mathrm{HCl}$ until a stable $I-V$ curve was obtained. Every sensor was calibrated for $\mathrm{pH}$ in phosphate buffered solutions.

\section{Focused Ion Beam Milling and SEM Imaging}

FETs were cut to a desired length, mounted on sample stubs and coated with $10 \mathrm{~nm}$ of chromium in a sputter coater on all sides (Q150T S Quorum). Transistors were imaged using a FIB-SEM (Cross Beam Workstation Auriga, Carl Zeiss). Tips of transistors were located using secondary electron imaging with an accelerating voltage of $5 \mathrm{keV}$. The FET tip was milled using a milling current of $200 \mathrm{pA}$ at a working distance of $5 \mathrm{~mm}$. Sections of $10 \mathrm{~nm}$ were ion milled and imaged by SEM with a $5 \mathrm{keV}$ acceleration, using a secondary electron in-lens detector.

\section{Attachment of Hexokinase}

Nano-FETs were immersed into a solution of $25 \%$ glutaraldehyde in water (Sigma-Aldrich) for at least $30 \mathrm{~min}$ while continuously sweeping the gate voltage and monitoring drainsource current. Afterward, also monitoring transistor performance, the probe was dipped into a solution of $500 \mathrm{U} / \mathrm{mL}$ hexokinase and glucose-6-phosphate dehydrogenase from $S$. cerevisiae (Sigma-Aldrich) for at least $30 \mathrm{~min}$.

\section{Measurements on Living Cells}

$\mathrm{pH}$ and ATP measurements to investigate cells/tissues were performed in unbuffered media containing $120 \mathrm{mM} \mathrm{NaCl}, 5 \mathrm{mM} \mathrm{KCl}, 5 \mathrm{mM} \mathrm{MgCl}_{2}$, and $20 \mathrm{mM}$ glucose in the case of ATP measurements. Prior to cell measurements, each ATP sensor was calibrated using a pH adjusted solution of adenosine $5^{\prime}$-triphosphate disodium salt hydrate (Sigma-Aldrich) in the same medium used for ATP measurements on cells. The SICM setup used for positioning of the nanobiosensor was described elsewhere.18 Movements of the sensors with respect to cell specimens were performed using stepper motors. The measured distance from cells is the position of the motor with respect to the point of closest approach shortly before touching the cell with the probe.

\section{Cell Culture}

The human malignant melanoma cell line A375 M and human immortal melanocyte cell line Hermes 3A were all obtained from the Wellcome Trust Functional Genomics Cell Bank (St George's, University of London, UK). Cell culture medium and reagents were purchased from Sigma-Aldrich. Melanoma cells were grown in RPMI 1640 medium with 10\% fetal 
calf serum and supplemented with L-glutamine $(2 \mathrm{mM})$, penicillin (100 U per $\mathrm{mL})$, and streptomycin (100 $\mu \mathrm{g}$ per $\mathrm{mL})$. Melanocytes were grown in RPMI 1640 medium supplemented with fetal calf serum (10\%), 12-0-tetradecanoyl phorbol acetate (200 nM), cholera toxin $(200 \mathrm{pM})$, human stem cell factor $(10 \mathrm{ng} / \mathrm{mL})$ and endothelin $1(10 \mathrm{nM})$. Cells were kept in a $10 \% \mathrm{CO}_{2}$ incubator at $37{ }^{\circ} \mathrm{C}$ and were subcultured at $75 \%$ confluence.

\section{Isolation of Rat Ventricular Myocyte}

The investigation conforms to the Guide for the Care and Use of Laboratory Animals published by the US National Institutes of Health (NIH Publication No. 85-23, revised 1996). Cardiac myocytes from adult rats were isolated as previously described.48 Briefly, male Sprague-Dawley rats were heparinized, killed by cervical dislocation, and the heart was rapidly excised and placed in ice-cold Krebs-Henseleit (KH) solution of composition (mM): $\mathrm{NaCl}, 119 ; \mathrm{KCl}, 4.7 ; \mathrm{MgSO}_{4}, 0.94 ; \mathrm{KH}_{2} \mathrm{PO}_{4}, 1.2 ; \mathrm{NaHCO}_{3}$, 25; glucose, 11.5; $\mathrm{CaCl}_{2}, 1$; and equilibrated to $\mathrm{pH} 7.4$ with $95 \% \mathrm{O}_{2} / 5 \% \mathrm{CO}_{2}$. A Langendorff perfusion method was used and the interventricular septum with the left ventricle was cut and shaken in $100 \% \mathrm{O}_{2}$ enzyme-containing solution for $5 \mathrm{~min}$. The supernatant was centrifuged at $400 \mathrm{~g}$ for $1 \mathrm{~min}$ at room temperature. Cells were washed and resuspended in the solution with 200 $\mu \mathrm{mol} / \mathrm{L}$ calcium.

\section{Breast Cancer Tissue Sample Preparation}

The samples were retrieved from patients undergoing mastectomy for primary breast cancer. All patients had consented under the Imperial College Tissue Bank Ethics 12/WA/0996 using the Imperial College Tissue Bank and Imperial College Healthcare NHS Trust Consent Form, following consultation with a health professional and being given the opportunity to read the Imperial College Tissue Bank Patient Information Sheet for the Use of Left Over Tissue. The samples were cut from the fresh specimen of tumor by the histopathologist and immediately placed in Eagle's medium and kept at $4{ }^{\circ} \mathrm{C}$ until the experiment was ready to be performed.

\section{Supporting Information}

Refer to Web version on PubMed Central for supplementary material.

\section{Acknowledgments}

This work was supported by Biotechnology and Biological Sciences Research Council BB/L005816/1, Engineering and Physical Sciences Research Council EP/1007482/1, the Wellcome Trust 108429 and 090594, and British Heart Foundation 12/18/30088. Y.T. is supported by Japan Science and Technology Agency PRESTO. M.L. is funded by the Graham Dixon Charitable Trust WHCF_G00000. J.C. and W.S. acknowledge financial support by the Deutsche Forschungsgemeinschaft in the framework of the Cluster of Excellence RESOLV (EXC1069).

\section{References}

(1). Qing Q, Jiang Z, Xu L, Gao R, Mai L, Lieber CM. Free-Standing Kinked Nanowire Transistor Probes for Targeted Intracellular Recording in Three Dimensions. Nat Nanotechnol. 2014; 9:142-147. [PubMed: 24336402]

(2). Tian B, Cohen-Karni T, Qing Q, Duan X, Xie P, Lieber CM. Three-Dimensional, Flexible Nanoscale Field-Effect Transistors as Localized Bioprobes. Science. 2010; 329:830-834. [PubMed: 20705858] 
(3). Park SJ, Kwon OS, Lee SH, Song HS, Park TH, Jang J. Ultrasensitive Flexible Graphene Based Field-Effect Transistor (FET)-Type Bioelectronic Nose. Nano Lett. 2012; 12:5082-5090. [PubMed: 22962838]

(4). Patolsky F, Zheng G, Lieber CM. Fabrication of Silicon Nanowire Devices for Ultrasensitive, Label-Free, Real-Time Detection of Biological and Chemical Species. Nat Protoc. 2006; 1:17111724. [PubMed: 17487154]

(5). Janata J, Josowicz M. Conducting Polymers in Electronic Chemical Sensors. Nat Mater. 2003; 2:19-24. [PubMed: 12652667]

(6). Song HS, Kwon OS, Lee SH, Park SJ, Kim U-K, Jang J, Park TH. Human Taste ReceptorFunctionalized Field Effect Transistor as a Human-Like Nanobioelectronic Tongue. Nano Lett. 2013; 13:172-178. [PubMed: 23176205]

(7). Balint R, Cassidy NJ, Cartmell SH. Conductive Polymers: Towards a Smart Biomaterial for Tissue Engineering. Acta Biomater. 2014; 10:2341-2353. [PubMed: 24556448]

(8). Yoon H, Ko S, Jang J. Field-Effect-Transistor Sensor Based on Enzyme-Functionalized Polypyrrole Nanotubes for Glucose Detection. J Phys Chem B. 2008; 112:9992-9997. [PubMed: 18646791]

(9). Wang Y, Noel J-M, Velmurugan J, Nogala W, Mirkin MV, Lu C, Guille Collignon M, Lemaitre F, Amatore C. Nanoelectrodes for Determination of Reactive Oxygen and Nitrogen Species Inside Murine Macrophages. Proc Natl Acad Sci U S A. 2012; 109:11534-11539. [PubMed: 22615353]

(10). Schulte A, Schuhmann W. Single-Cell Microelectrochemistry. Angew Chem Int Ed. 2007; 46:8760-8777.

(11). Trouillon R, Passarelli MK, Wang J, Kurczy ME, Ewing AG. Chemical Analysis of Single Cells. Anal Chem. 2013; 85:522-542. [PubMed: 23151043]

(12). Akhavan O, Ghaderi E, Rahighi R. Toward Single-DNA Electrochemical Biosensing by Graphene Nanowalls. ACS Nano. 2012; 6:2904-2916. [PubMed: 22385391]

(13). Akhavan O, Ghaderi E, Rahighi R, Abdolahad M. Spongy Graphene Electrode in Electrochemical Detection of Leukemia at Single-Cell Levels. Carbon. 2014; 79:654-663.

(14). Takahashi Y, Shevchuk AI, Novak P, Zhang Y, Ebejer N, Macpherson JV, Unwin PR, Pollard AJ, Roy D, Clifford CA, Shiku H, et al. Multifunctional Nanoprobes for Nanoscale Chemical Imaging and Localized Chemical Delivery at Surfaces and Interfaces. Angew Chem Int Ed. 2011; 50:9638-9642.

(15). McKelvey K, Paulose Nadappuram B, Actis P, Takahashi Y, Korchev YE, Matsue T, Robinson C, Unwin PR. Fabrication, Characterization, and Functionalization of Dual Carbon Electrodes as Probes for Scanning Electrochemical Microscopy (SECM). Anal Chem. 2013; 85:7519-7526. [PubMed: 23795948]

(16). Actis P, Tokar S, Clausmeyer J, Babakinejad B, Mikhaleva S, Cornut R, Takahashi Y, López Córdoba A, Novak P, Shevchuck AI, Dougan JA, et al. Electrochemical Nanoprobes for SingleCell Analysis. ACS Nano. 2014; 8:875-884. [PubMed: 24377306]

(17). Clausmeyer J, Actis P, López Córdoba A, Korchev Y, Schuhmann W. Nanosensors for the Detection of Hydrogen Peroxide. Electrochem Commun. 2014; 40:28-30.

(18). Takahashi Y, Shevchuk AI, Novak P, Babakinejad B, Macpherson J, Unwin PR, Shiku H, Gorelik J, Klenerman D, Korchev YE, Matsue T. Topographical and Electrochemical Nanoscale Imaging of Living Cells Using Voltage-Switching Mode Scanning Electrochemical Microscopy. Proc Natl Acad Sci U S A. 2012; 109:11540-11545. [PubMed: 22611191]

(19). Paulose Nadappuram B, McKelvey K, Al Botros R, Colburn AW, Unwin PR. Fabrication and Characterization of Dual Function Nanoscale pH-Scanning Ion Conductance Microscopy (SICM) Probes for High Resolution pH Mapping. Anal Chem. 2013; 85:8070-8074. [PubMed: 23919610]

(20). Swietach P, Vaughan-Jones RD, Harris AL, Hulikova A. The Chemistry, Physiology and Pathology of pH in Cancer. Philos Trans R Soc B. 2014; 369:20130099.

(21). Daniel C, Bell C, Burton C, Harguindey S, Reshkin SJ, Rauch C. The Role of Proton Dynamics in the Development and Maintenance of Multidrug Resistance in Cancer. Biochim Biophys Acta Mol Basis Dis. 2013; 1832:606-617. 
(22). Parks SK, Chiche J, Pouyssegur J. pH Control Mechanisms of Tumor Survival and Growth. J Cell Physiol. 2011; 226:299-308. [PubMed: 20857482]

(23). Burnstock G. Purinergic Signalling: From Discovery to Current Developments. Exp Physiol. 2014; 99:16-34. [PubMed: 24078669]

(24). Zhang Y, Sanchez D, Gorelik J, Klenerman D, Lab M, Edwards C, Korchev Y. Basolateral P2 × 4-like Receptors Regulate the Extracellular ATP-Stimulated Epithelial Na+ Channel Activity in Renal Epithelia. Am J Physiol Renal Physiol. 2007; 292:F1734-40. [PubMed: 17356127]

(25). Gorelik J, Zhang Y, Sánchez D, Shevchuk A, Frolenkov G, Lab M, Klenerman D, Edwards C, Korchev Y. Aldosterone Acts Via an ATP Autocrine/Paracrine System: the Edelman ATP Hypothesis Revisited. Proc Natl Acad Sci U S A. 2005; 102:15000-15005. [PubMed: 16230642]

(26). Burnstock G. Pathophysiology and Therapeutic Potential of Purinergic Signaling. Pharmacol Rev. 2006; 58:58-86. [PubMed: 16507883]

(27). Falzoni S, Donvito G, Di Virgilio F. Detecting Adenosine Triphosphate in the Pericellular Space. Interface Focus. 2013; 3:20120101. [PubMed: 23853707]

(28). Okada SF, Nicholas RA, Kreda SM, Lazarowski ER, Boucher RC. Physiological Regulation of ATP Release at the Apical Surface of Human Airway Epithelia. J Biol Chem. 2006; 281:2299223002. [PubMed: 16754672]

(29). Zhang Y, Phillips GJ, Li Q, Yeung ES. Imaging Localized Astrocyte ATP Release with Firefly Luciferase Beads Attached to the Cell Surface. Anal Chem. 2008; 80:9316-9325. [PubMed: 19551993]

(30). Gourine AV, Dale N, Llaudet E, Poputnikov DM, Spyer KM, Gourine VN. Release of ATP in the Central Nervous System During Systemic Inflammation: Real-Time Measurement in the Hypothalamus of Conscious Rabbits. J Physiol. 2007; 585:305-316. [PubMed: 17901122]

(31). Gourine AV, Llaudet E, Dale N, Spyer KM. ATP is a Mediator of Chemosensory Transduction in the Central Nervous System. Nature. 2005; 436:108-111. [PubMed: 16001070]

(32). Migita S, Ozasa K, Tanaka T, Haruyama T. Enzyme-Based Field-Effect Transistor for Adenosine Triphosphate (ATP) Sensing. Anal Sci. 2007; 23:45-48. [PubMed: 17213622]

(33). Dutta AK, Sabirov RZ, Uramoto H, Okada Y. Role of ATP-Conductive Anion Channel in ATP Release From Neonatal Rat Cardiomyocytes in Ischaemic or Hypoxic Conditions. J Physiol. 2004; 559:799-812. [PubMed: 15272030]

(34). Hecht E, Liedert A, Ignatius A, Mizaikoff B, Kranz C. Local Detection of Mechanically Induced ATP Release From Bone Cells With ATP Microbiosensors. Biosens Bioelectron. 2013; 44:27-33. [PubMed: 23384767]

(35). Shirale DJ, Bangar MA, Chen W, Myung NV, Mulchandani A. Effect of (L:D) Aspect Ratio on Single Polypyrrole Nanowire FET Device. J Phys Chem C. 2010; 114:13375-13380.

(36). Burd R, Wachsberger PR, Biaglow JE, Wahl ML, Lee I, Leeper DB. Absence of Crabtree Effect in Human Melanoma Cells Adapted to Growth at Low pH: Reversal by Respiratory Inhibitors. Cancer Res. 2001; 61:5630-5635. [PubMed: 11454717]

(37). Halaban R, Patton RS, Cheng E, Svedine S, Trombetta ES, Wahl ML, Ariyan S, Hebert DN. Abnormal Acidification of Melanoma Cells Induces Tyrosinase Retention in the Early Secretory Pathway. J Biol Chem. 2002; 277:14821-14828. [PubMed: 11812790]

(38). Poghossian A, Ingebrandt S, Offenhäusser A, Schöning MJ. Field-Effect Devices for Detecting Cellular Signals. Semin Cell Dev Biol. 2009; 20:41-48. [PubMed: 19429490]

(39). Fromherz P, Offenhausser A, Vetter T, Weis J. A Neuron-Silicon Junction: A Retzius Cell of the Leech On an Insulated-Gate Field-Effect Transistor. Science. 1991; 252:1290-1293. [PubMed: 1925540]

(40). Duan X, Gao R, Xie P, Cohen-Karni T, Qing Q, Choe HS, Tian B, Jiang X, Lieber CM. Intracellular Recordings of Action Potentials by an Extracellular Nanoscale Field-Effect Transistor. Nat Nanotechnol. 2012; 7:174-179. [PubMed: 22179566]

(41). Son D, Park SY, Kim B, Koh JT, Kim TH, An S, Jang D, Kim GT, Jhe W, Hong S. Nanoneedle Transistor-Based Sensors for the Selective Detection of Intracellular Calcium Ions. ACS Nano. 2011; 5:3888-3895. [PubMed: 21495678]

(42). Kwiat M, Stein D, Patolsky F. Nanotechnology Meets Electrophysiology. Curr Opin Biotechnol. 2013; 24:654-663. [PubMed: 23419931] 
(43). Korostynska O, Arshak K, Gill E, Arshak A. Review on State-Of-The-Art in Polymer Based pH Sensors. Sensors. 2007; 7:3027-3042.

(44). Ding C, Tian Y. Gold Nanocluster-Based Fluorescence Biosensor for Targeted Imaging in Cancer Cells and Ratiometric Determination of Intracellular pH. Biosens Bioelectron. 2014; 65C:183190. [PubMed: 25461156]

(45). Gerasimovskaya EV, Ahmad S, White CW, Jones PL, Carpenter TC, Stenmark KR. Extracellular ATP is an Autocrine/Paracrine Regulator of Hypoxia-Induced Adventitial Fibroblast Growth. Signaling Through Extracellular Signal-Regulated Kinase-1/2 and the Egr-1 Transcription Factor. J Biol Chem. 2002; 277:44638-44650. [PubMed: 12244041]

(46). Wang WU, Chen C, Lin K-h, Fang Y, Lieber CM. Label-Free Detection of Small-MoleculeProtein Interactions by Using Nanowire Nanosensors. Proc Natl Acad Sci U S A. 2005; 102:3208-3212. [PubMed: 15716362]

(47). Paulose Nadappuram B, McKelvey K, Byers JC, Güell AG, Colburn AW, Lazenby RA, Unwin PR. Quad-Barrel Multifunctional Electrochemical and Ion Conductance Probe for Voltammetric Analysis and Imaging. Anal Chem. 2015; 87:3566-3573. [PubMed: 25719392]

(48). Gorelik J, Yang LQ, Zhang Y, Lab M, Korchev Y, Harding SE. A Novel Z-Groove Index Characterizing Myocardial Surface Structure. Cardiovasc Res. 2006; 72:422-429. [PubMed: 17054929] 


\section{Spearhead Nano FET}

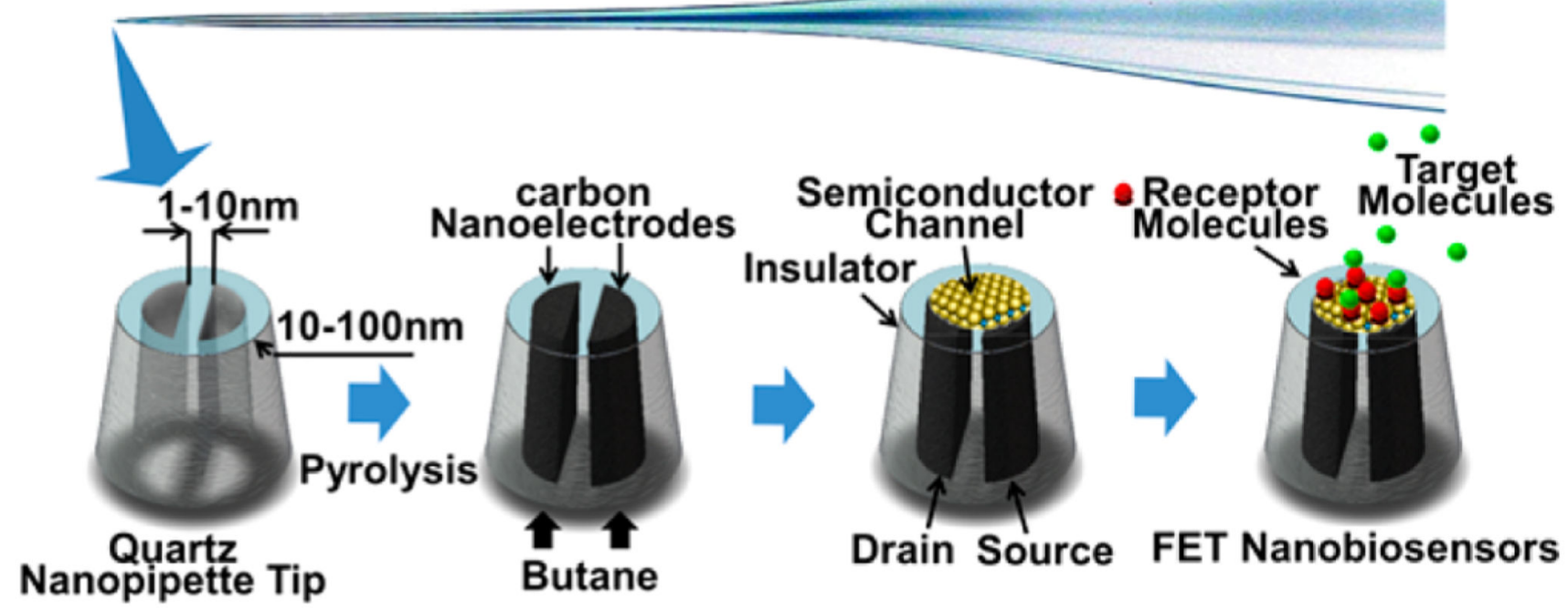

Figure 1. A nanometer-scale field-effect-transistor is created by depositing a thin layer of semiconductor material on the tip of spear-shaped dual carbon nanoelectrodes fabricated by pyrolytic decomposition of butane inside $\Theta$-nanopipettes. The two individually addressable electrodes serve as drain and source. Immobilising suitable recognition biomolecules on the semiconductor transistor channel yields selective FET biosensors. 

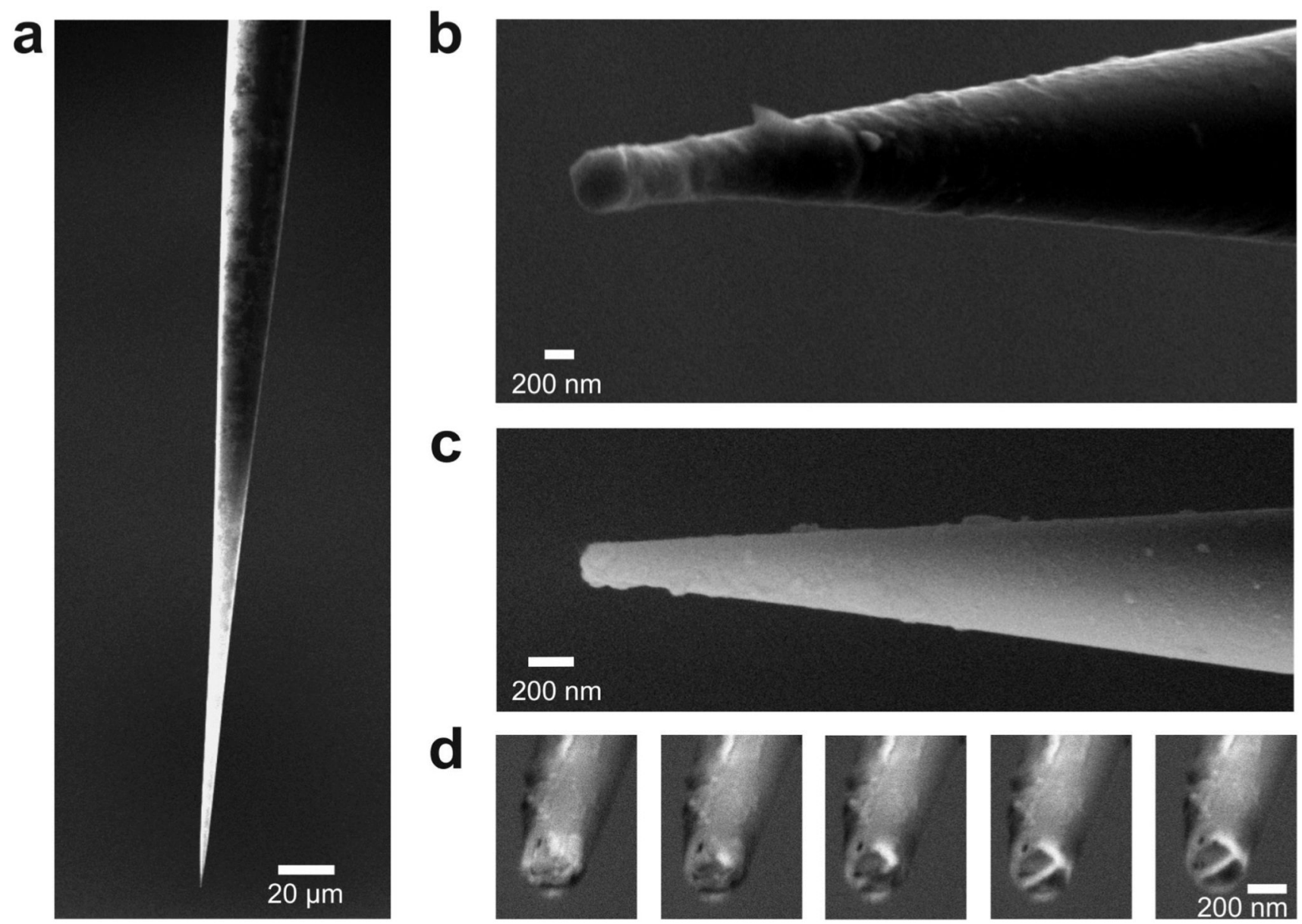

Figure 2. PPy forms the transistor channel of a spearhead nano-FET on dual carbon electrodes. SEM images of spearhead FETs in different magnification $(a-c)$. Series of cross-section images taken at different stages during FIB milling to assess the thickness of the PPy deposit (d). 

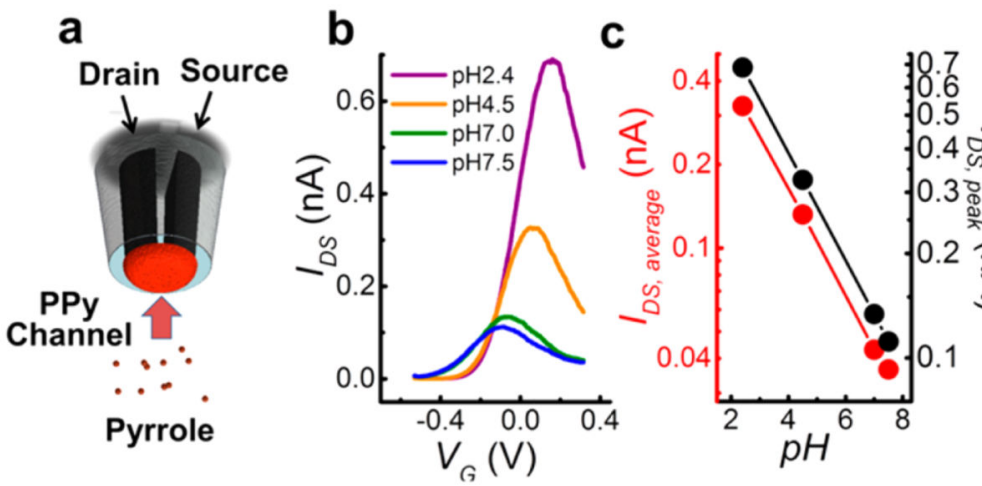

g

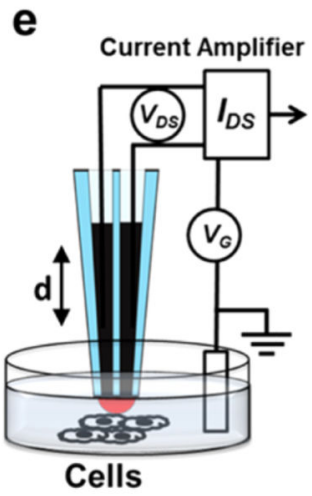

$f$

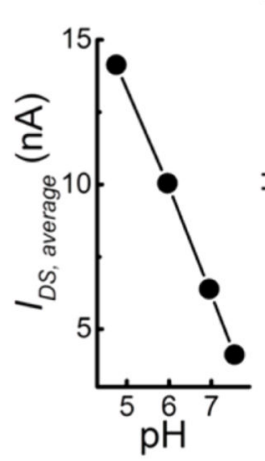

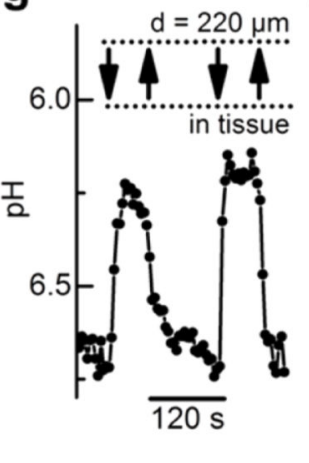
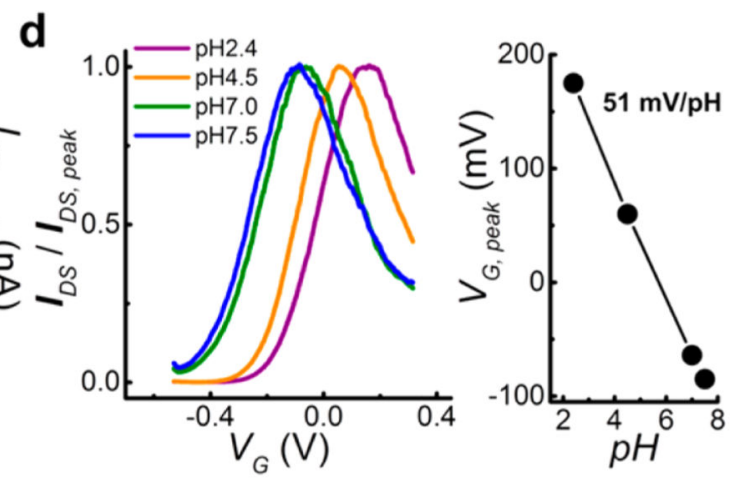

h

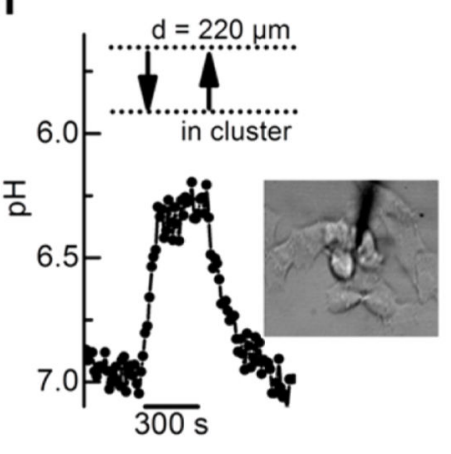

i

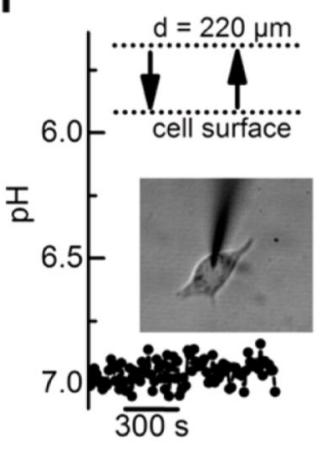

Figure 3. A spearhead nano-FET made by deposition of polypyrrole to comprise the channel (a) works as a highly sensitive pH biosensor. From $I-V_{G}$ curves (b) changes in pH value can be measured as change of average drain-source current or drain-source peak currents (c) as well as shift in gate voltage (d). The $\mathrm{pH}$-sensitive PPy nano-FET is applied to measure the local $\mathbf{p H}$ in the microenvironment of cell samples (e). Prior to cell measurements the PPy nano-FET is calibrated with physiological $\mathrm{pH}$ variations from 5 to 7.5 (f). Local pH measurements by alternating vertical approach and withdrawal of the PPy nano-FET probe to breast cancer tissue (g), a cluster of melanoma cells (h), and a single melanoma cell (i). 


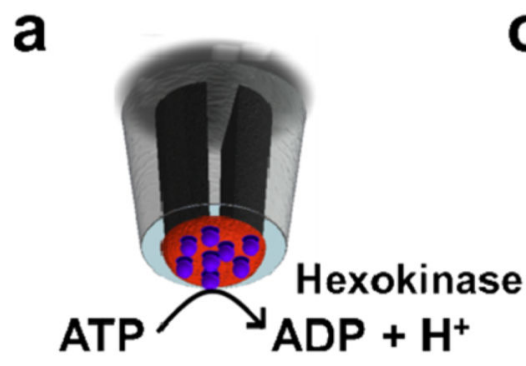

b
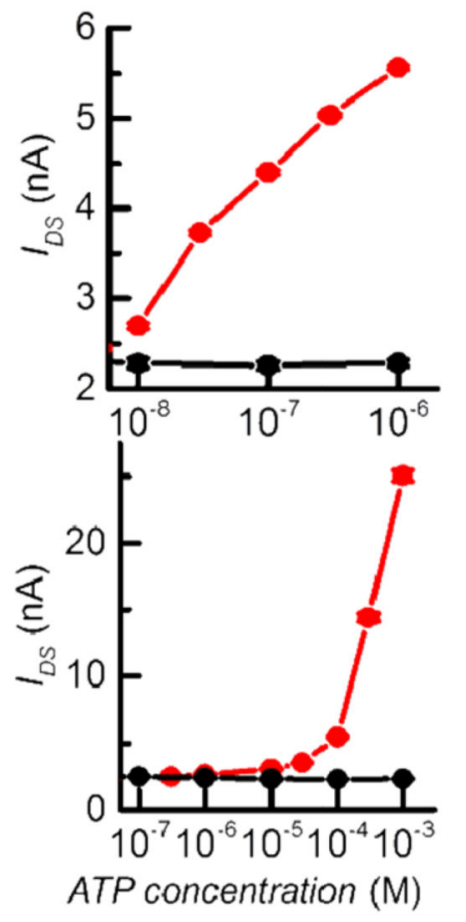
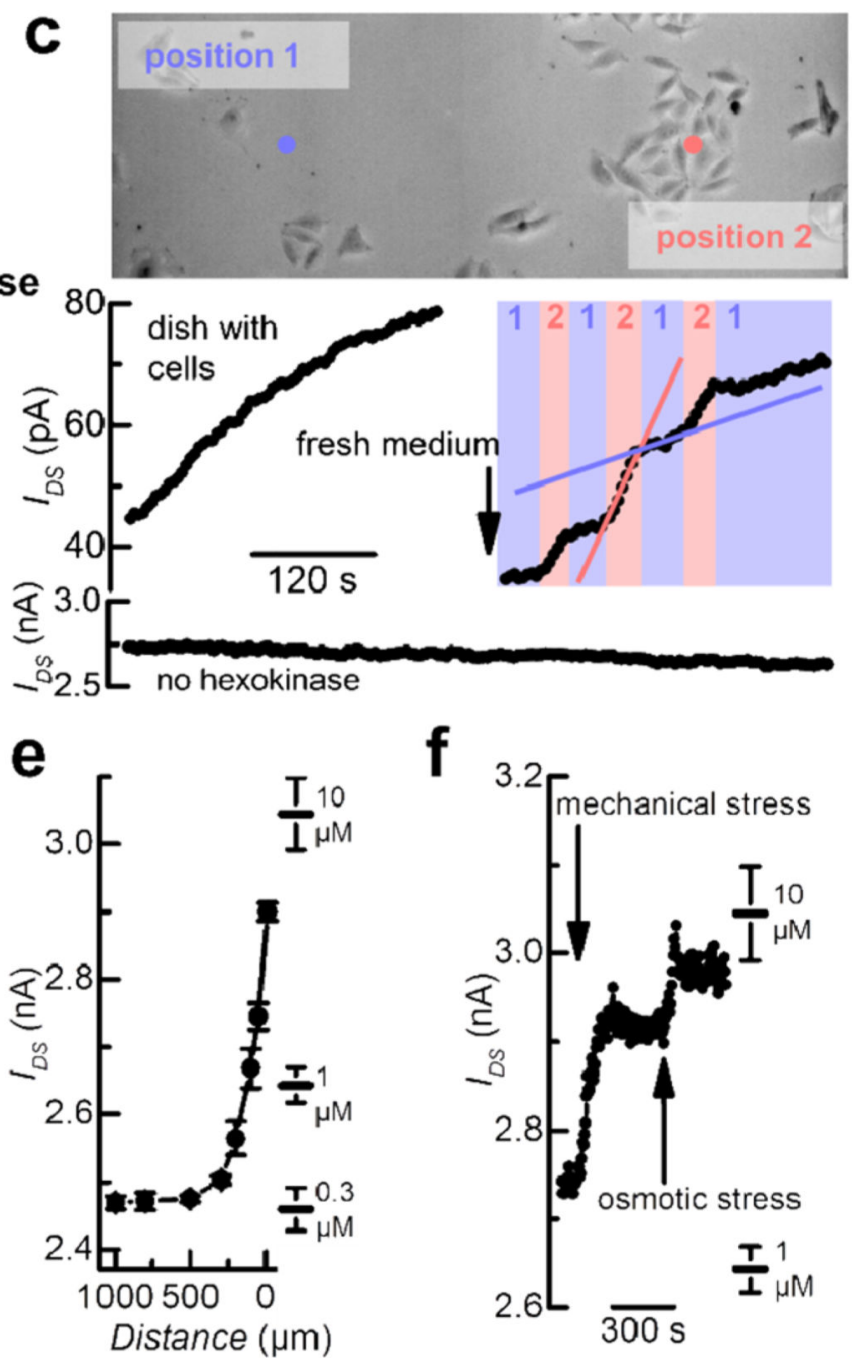

f

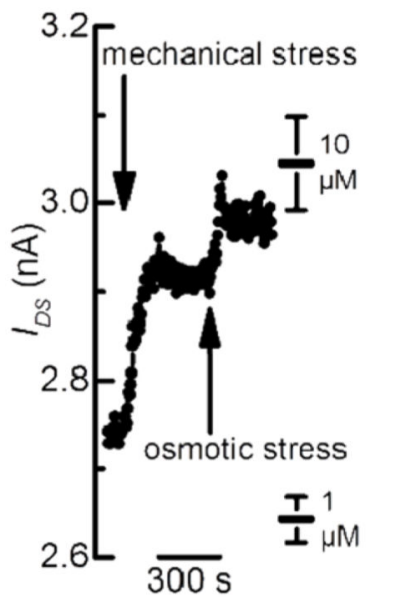

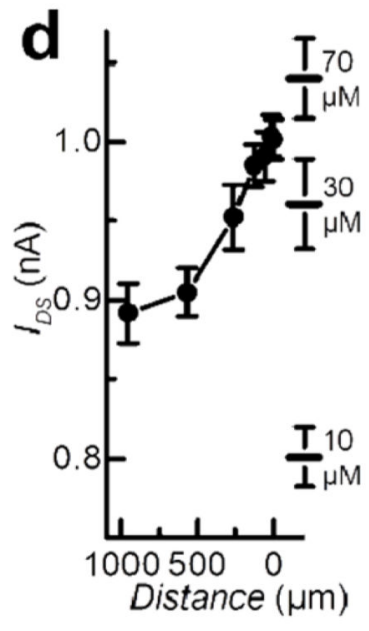

g
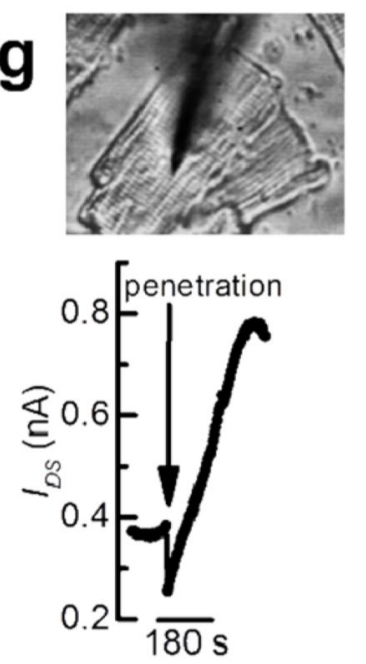

Figure 4. PPy nano-FET probe detects pH changes caused by hexokinase to perform highly localized ATP measurements for cell analysis. Immobilizing hexokinase to the tip of the probe creates a highly sensitive biosensor (a). Calibration curves are shown for two individual sensors, black-dot traces show the control experiment of a nano-FET not modified with hexokinase (b). Real-time ATP measurements over a nonpopulated spot and a group of melanoma cells demonstrate the high rate of ATP release from the cells (c). ATP gradients released from an isolated melanoma cell are measured by vertical approach of the sensor (d). Localized ATP measurements are also performed on a single cardiomyocyte (e-g). The cardiomyocyte produces a vertical gradient from its proximate microenvironment into the bulk solution (e). Additional ATP release is induced by touching the cell with the sensor and adding water to the solution to create osmotic stress (f). The probe allows for penetration into the cardiomyocyte (g). 
Table 1

Current FET Sensor Technologies for Physiological Parameter Measurements at Single Cells

\begin{tabular}{|c|c|c|c|c|c|}
\hline FET design & measured quantities & nanometric FET & $\begin{array}{c}\text { used for } \\
\text { intracellular } \\
\text { measurements }\end{array}$ & $\begin{array}{c}\text { used for } \\
\text { extracellular } \\
\text { analyte mapping }\end{array}$ & ref \\
\hline flat Si channel & electric potential & no & no & no & 39 \\
\hline $\begin{array}{l}\text { free-standing kinked } \mathrm{Si} \\
\text { nanowire }\end{array}$ & electric potential & yes & yes & no & 1 \\
\hline $\begin{array}{l}\text { upright } \mathrm{SiO}_{2} \text { nanotube branch } \\
\text { on top of a nanoscale FET }\end{array}$ & electric potential & yes & yes & no & 40 \\
\hline $\begin{array}{l}\text { gold-coated pipet with carbon } \\
\text { nanotube network as channel }\end{array}$ & $\begin{array}{l}\mathrm{Ca}^{2+} \text { concentration (range } 100 \\
\mathrm{pM}-1 \mathrm{mM} \text { ) }\end{array}$ & yes & yes & no & 41 \\
\hline $\begin{array}{l}\text { PPy on dual carbon } \\
\text { nanoelectrode }\end{array}$ & $\begin{array}{l}\mathrm{pH}(\text { range } 1-7.5) \text { ATP } \\
\text { concentration (range } 10 \mathrm{nM}-1 \\
\mathrm{mM})\end{array}$ & yes & yes & yes & this work \\
\hline
\end{tabular}

